\title{
Interface Sintaxe-Semântica: em defesa de uma abordagem construcionista para a ordem VS do português brasileiro
}

\section{Syntax-Semantics interface: making the case for a construction grammar approach to Brazilian Portuguese VS order}

1 Doutor em Linguística pela Universidade Federal do Rio de Janeiro. Professor Filunto do Departam Jo do Linguisticá Graduação em lingústica da UFRJ. diogopinheiro@letras ufri.br

Doutora em Linguística pela Universidade Federal do Rio de Janeiro. Professora Associada IV do Departamento de Linguística e Filologia e Membro do Programa de Pós-Graduação em Linguistica da UFRJ. Coordenadora do Laboratório de Pesquisas em Linguística Cognitiva (LINC).

lilianferrari@uol.com.br

Diogo Pinheiro ${ }^{1}$, Lilian Ferrari²

RESUMO: Inserindo-se no quadro teórico da Gramática de Construções (GOLDBERG, 1995; 2006; CROFT, 2001; dentre outros), este trabalho se ocupa de um tema já extensamente discutido na literatura: o problema da inversão do sujeito no português brasileiro (PB). Buscamos mostrar que o esquema verbo-sujeito do PB se constitui como uma unidade simbólica, isto é, uma construção gramatical. Para isso, procedemos a uma análise da semântica da construção VS, buscando descrevê-la em dois níveis (nos termos de Verhagen (2005)): o nível do objeto (associado à cena efetivamente predicada pela construção) e o nível do sujeito (ligado ao modo como a cena é construída/conceptualizada pelo falante). Argumentamos também que a correlação, comumente encontrada na literatura, entre sujeito pós-verbal, de um lado, e inacusatividade ou não-agentividade, de outro, decorre naturalmente da proposta apresentada aqui.

Palavras-chave: Ordem VS; Gramática de Construções; Semântica Cognitiva; Frame semântico.

ABSTRACT: This papers aims at developing a construction grammar approach to subject inversion in Brazilian Portuguese. After arguing that the verb-subject structure is best understood as a grammatical construction (thus a symbolic unit), we go on to analyze the semantic dimension of the VS construction in two separate levels: Verhagen's (2005) object-level (the construction's predication) and subject-level (the construal imposed on the predication). It is also argued that the correlations often found between subject inversion, on the one hand, and unnacusativity or lack of agentivity, on the other, can be regarded as by-products of the general proposal advanced here.

KEYwoRDS: VS order; Construction Grammar; Cognitive Semantics; Semantic frame. 


\section{Primeiras palavras}

o atrair a atenção de pesquisadores alinhados às mais diversas correntes teóricas, o tema da posição do sujeito tem servido como campo de testes para diferentes teorias linguísticas e modelos de gramática. No que diz respeito, em particular, ao caso do português brasileiro (PB), o problema da inversão do sujeito tem motivado um número elevado de trabalhos (NASCIMENTO, 1984; BERLINCK, 1989; FERRARI, 1990; PEZATTI, 1992; FIGUEIREDO SILVA, 1996; NARO; VOTRE; 1999; COELHO, 2000; PILATTI, 2002; dentre muitos outros). De maneira geral, esses estudos se fazem a seguinte pergunta: sob que condições o falante do PB emprega o sujeito em posição pós-verbal?

As respostas já oferecidas para essa pergunta residem, sistematicamente, na interface entre a sintaxe e algum outro domínio do conhecimento gramatical. Tomada em conjunto, essa literatura parece sugerir que a inversão do sujeito no PB é sensível a:

i) propriedades lexicais: a inversão do sujeito é licenciada por verbos monoargumentais ou, alternativamente, por verbos inacusativos (interface sintaxe-léxico), como se vê em Nascimento (1984), Berlinck (1989) e Figueiredo Silva (1996);

ii) propriedades fonológicas: sujeitos mais pesados tendem a aparecer em posição pós-verbal (interface sintaxe-fonologia), como sugere Figueiredo Silva (1996);

iii) propriedades semânticas: sujeitos pós-verbais são não-agentivos (interface sintaxe-semântica), como sugere Pezatti (1992);

iv) propriedades pragmático-discursivas: sujeitos pós-verbais tendem a ser novos ou apresentam baixa topicalidade (interface sintaxediscurso), conforme Ferrari (1990) e Naro e Votre (1999).
Alinhando-se à tradição da linguística funcional-cognitiva, este artigo se insere entre aqueles que procuram associar a ordem VS do português brasileiro a certas propriedades semânticas específicas. No entanto, ele se diferencia dos tratamentos anteriores na medida em que adota uma perspectiva explicitamente construcionista - isto é, baseada no modelo conhecido como Gramática de Construções (GOLDBERG, 1995; 2006; CROFT, 2001).

Como se verá na seção 1, a premissa central da Gramática de Construções (GC) é a de que o conhecimento gramatical do falante pode ser integralmente descrito como um inventário de unidades simbólicas - isto é, pareamentos convencionais entre informações de forma e de significado - a que chamamos de construções gramaticais. Aqui, buscaremos mostrar que o esquema formal verbo-sujeito do PB está diretamente associado a uma especificação semântica própria, qualificando-se, portanto, como uma construção gramatical. Sob esse ponto de vista, o objetivo central deste trabalho é o de descrever o polo semântico da construção VS do português brasileiro, delineando sua base conceptual.

Os dados aqui discutidos advêm de duas fontes: o corpus Big Brother Brasil 10 (BBB 10) e o corpus Discurso \& Gramática (D\&G). O primeiro é formado pela transcrição de aproximadamente 60 horas de interação conversacional espontânea, obtidas por meio de gravação da décima edição do reality show Big Brother Brasil, veiculado pela Rede Globo no ano de 2010. O segundo, disponível no endereço eletrônico http://www. discursoegramatica.letras.ufrj.br, inclui dados de língua falada e escrita relativos a cinco municípios brasileiros (Rio de Janeiro, Natal, Rio Grande, Juiz de Fora e Niterói) e divididos de acordo com cinco modalidades textuais (narrativa de experiência pessoal, narrativa recontada, descrição de local, relato de procedimento e relato de opinião). Para esta pesquisa, foram utilizados apenas os dados de língua falada. 
O texto está organizado como segue. A próxima seção se ocupa da fundamentação teórico-descritiva, apresentando o modelo da Gramática de Construções. Em seguida, a seção 2 delimita o objeto específico deste estudo. As seções 3 e 4 constituem o cerne do artigo: enquanto a primeira busca delinear uma base conceptual para a construção VS do português brasileiro, a segunda discute, especificamente, o problema da compatibilização entre a construção VS e verbos pertencentes a diferentes classes semânticas. Por fim, a seção 5 traz as considerações finais.

\section{Por uma gramática de construções: a língua como inventário de unidades simbólicas}

Surgida na década de 80 do século passado, na Universidade da Califórnia, Berkeley, em torno de nomes como Charles Fillmore, Paul Kay e George Lakoff, a Gramática de Construções (GC) se constitui, essencialmente, como um modelo não derivacional de gramática. Isso significa que a GC dispensa o recurso a quaisquer tipos de derivações sintáticas ou operações computacionais, passando a entender a língua como uma rede articulada de construções gramaticais.

Tecnicamente, uma construção gramatical é um pareamento convencional entre uma forma (fonológica, prosódica e/ou morfossintática) e um significado (aí incluídas, de maneira ampla, quaisquer informações semânticas, pragmáticas, discursivas ou funcionais). Interessantemente, essa definição se aplica tanto às palavras (um item como "árvore" é a combinação de uma sequência de fonemas com um determinado conceito) quanto a estruturas morfológicas e padrões sentenciais. O Quadro 1 ilustra essa ideia.

À luz da GC, todos os elementos do Quadro 1 são unidades simbólicas, formadas pelo pareamento convencional entre informações de forma e de
Quadro 1 - 0 continuum léxico-sintaxe

\begin{tabular}{|c|c|}
\hline Construção & Exemplos \\
\hline Palavra & a, abacaxi, gato \\
\hline Estrutura morfológica & des-V (ex: desligar), N-eiro (ex: jornaleiro) \\
\hline Expressão idiomática preenchida & chutar o balde, bater as botas \\
\hline $\begin{array}{l}\text { Idiomatismo formal } \\
\text { (parcialmente preenchido) }\end{array}$ & $\begin{array}{l}\text { dar uma de ADJ (ex: dar uma de maluco); que } \\
\text { mané X (ex: que mané descanso; que mané "não } \\
\text { vai ter Copa"). }\end{array}$ \\
\hline $\begin{array}{l}\text { Construção bitransitiva } \\
\text { SUJ V OD OI }\end{array}$ & $\begin{array}{l}\text { SUJ V OD OI } \\
\text { (ex: Francisco deu uma peteca para o gato) }\end{array}$ \\
\hline Construção passiva & $\begin{array}{l}\text { SUJ AUX SV } \\
\text { (ex: A peteca foi comprí } \\
P_{\text {POR }} \\
\end{array}$ \\
\hline
\end{tabular}

Fonte: Adaptado de Goldberg (2013, p. 17).

significado. Note-se que a forma pode ser fonológica (como em "abacaxi”), fonológica e sintática (como em "chutar o balde") ou exclusivamente sintática (como em SUJ V OD OI). Quanto às informações de significado, elas podem incluir tanto um conteúdo semântico específico (por exemplo, a ideia de transferência de posse na construção bitransitiva) quanto informações de natureza funcional ou discursiva (como a especificação de que, na construção passiva, a agente tem sua proeminência discursiva reduzida). A premissa central do modelo é a de que a totalidade do conhecimento linguístico do falante - de palavras a sentenças regulares, passando pelas estruturas morfológicas e padrões idiomáticos - pode ser representada de maneira uniforme, por meio do conceito de construção gramatical.

Essa premissa acarreta algumas rupturas. Notadamente, deixam de fazer sentido dicotomias como léxico $\mathrm{X}$ sintaxe (ou gramática) e idiomaticidade $\mathrm{X}$ composicionalidade. Afinal, do ponto de vista da GC, não há distinção qualitativa entre palavras, estruturas morfológicas, padrões idiomáticos (inteira ou parcialmente preenchidos) e esquemas sintático-semânticos abstratos: trata-se, em todos os casos, de construções gramaticais. A distinção 
entre elas não é de tipo, mas de grau: como se vê no quadro acima, existe um continuum de preenchimento fonológico cujos extremos são, de um lado, as construções inteiramente preenchidas e, de outro, os padrões totalmente abertos $^{1}$.

É preciso ressalvar, no entanto, que, à luz da GC, o conhecimento linguístico do falante não tem o formato de uma lista de entradas lexicais independentes. Em vez disso, assume-se que esse conhecimento pode ser representado sob a forma de uma rede de construções gramaticais interconectadas. Com efeito, embora os diferentes modelos construcionistas divirjam largamente quanto ao formato preciso dessa rede e aos tipos de links usados para estabelecer os vínculos entre construções, todos eles aderem à ideia de que o conhecimento linguístico não é uma coleção desestruturada de construções gramaticais, e sim um sistema complexo cuja organização interna é assegurada, no mínimo, pela existência de relações taxonômicas entre os elementos que o compõem.

Por fim, é preciso acrescentar uma palavra sobre o estatuto das relações gramaticais - como sujeito e objeto, por exemplo - no âmbito da GC. Em modelos construcionistas como a Gramática de Construções Radical (CROFT, 2001; 2013) e a Gramática de Construções Cognitiva (GOLDBERG, 1995; 2006; BOAS, 2013), aos quais subscrevemos, não se assume a existência de um conjunto de relações gramaticais com status de primitivos teóricos

\footnotetext{
${ }^{1}$ Pode ser útil enfatizar que a GC não postula a existência de qualquer tipo de continuum entre sintaxe e semântica: como o modelo se ancora de modo crucial na noção de signo - mais precisamente, uma espécie de versão expandida e enriquecida do signo saussuriano -, sintaxe (forma) e semântica (significado) são concebidas como faces de uma mesma moeda. Essas duas dimensões não se colocam, portanto, como pontos de um continuum, mas como os dois parâmetros constitutivos do signo - ou construção gramatical. Por outro lado, o que de fato se dispõe em um continuum são os diferentes tipos de construç̃os gramaticais, de acordo com o seu caráter mais ou menos preenchido. Esse continuum pode ser pence continuum 任 mamínio do
}

a serem definidos independentemente das construções em que se inserem. O ponto de partida, em vez disso, é sempre o próprio padrão construcional.

Na prática, isso significa o seguinte: quando usado, por exemplo, na expressão "construção verbo-sujeito", o termo "sujeito" deve ser entendido simplesmente como um atalho mnemônico para fazer referência a um slot particular dentro de uma construção gramatical determinada - um slot que pode ser instanciado por diferentes elementos, como se vê em chegou o homem / o fantasma / uma professora. Sob essa perspectiva, não há nenhuma garantia - e, sobretudo, nenhuma necessidade - de que o SN da construção SV (por exemplo) tenha comportamento gramatical análogo. Como a lógica do modelo é ascendente, ou bottom-up, admite-se a possibilidade de que o falante construa uma construção mais alta - isto é, mais abstrata - que seja não-marcada quanto à ordem linear dos constituintes e que, portanto, abarque os dois tipos de sujeito (o sujeito de SV e o sujeito de VS). Mas isso não é, de modo algum, um imperativo teórico-descritivo: é possível que o falante mantenha as duas construções separadas, sem uni-las em um nível mais alto da rede construcional.

Em suma, a ideia básica é a seguinte: os termos que nomeiam as relações gramaticais tradicionais podem até ser usados por conveniência didática como fazemos aqui com o termo "sujeito" -, mas eles não gozam efetivamente de qualquer estatuto teórico relevante. Nesse sentido, as relações gramaticais devem ser definidas sempre a partir da construção específica na qual elas se constituem ${ }^{2}$.

${ }_{2}^{2}$ Embora esse ponto seja defendido de modo mais explícito (e enfático) por Croft $(2001 ; 2013)$, muito em função da sua formação na tradição tipológico-funcional, ele também é aceito sem reservas, por exemplo, por Tomasello (2003) e por Goldberg (2006). Por outro lado, deve-se ressalvar que esta não é a perspectiva de Ronald Langacker, criador de um modelo construcionista próprio (LANGACKER, 1987; 1991; 2008). Para este autor, a categoria formal de sujeito está associada à categoria conceptual de trajetor ("trajector"), como se pode verificar nas referências aqui citadas. 
Em resumo, as premissas construcionistas adotadas neste trabalho são as seguintes:

i) o conhecimento linguístico do falante deve ser representado de forma declarativa, ou seja, sem o recurso a regras ou derivações sintáticas;

ii) o conhecimento linguístico do falante deve ser descrito integralmente como um inventário de construções gramaticais, as quais são definidas, por sua vez, como pareamentos convencionais de informações de forma (fonológicas, prosódicas, morfossintáticas) e informações de significado (semânticas, pragmáticas, discursivas, funcionais);

iii) construções gramaticais variam quanto ao seu grau de preenchimento e à sua complexidade estrutural interna, recobrindo, com isso, os domínios tradicionais do léxico, da morfologia e da sintaxe (conforme o Quadro 1);

iv) o inventário de construções gramaticais não é uma coleção desestruturada de itens, mas uma rede de elementos interconectados; e

v) as relações gramaticais não têm o estatuto de primitivos teóricos, sendo, em vez disso, definidas sempre intraconstrucionalmente.

\section{Construções de inversão do sujeito do PB: delimitando o objeto deste estudo}

Se o conhecimento linguístico do falante pode ser integralmente descrito como uma vasta rede de construções gramaticais interconectadas, a delimitação do nosso objeto de estudo passa pela seguinte pergunta: ao se debruçar sobre a ordem VS no PB, que porção da rede construcional dessa língua o trabalho se propõe a descrever?
Ao que tudo indica, a inversão do sujeito no PB é um fenômeno complexo e multifacetado, que se manifesta em diferentes contextos e pode estar associado a uma variedade de funções pragmático-discursivas. Sob uma perspectiva construcionista, isso significa que a ordem verbo-sujeito não deverá corresponder a uma construção gramatical única, mas a uma família de construções gramaticais. A título de levantamento preliminar, propomos um elenco de nove construções gramaticais nas quais a ordem VS pode se manifestar no PB, conforme o Quadro $2^{3}$.

Quadro 2 - Levantamento preliminar das construções de inversão do sujeito no PB

\begin{tabular}{|l|l|}
\hline \multicolumn{1}{|c|}{ Construção Gramatical } & \multicolumn{1}{c|}{ Exemplo } \\
1. Marcação de foco sentencial & Furou o pneu. \\
2. Marcação de foco identificacional & Até agora, chegou o Carlos e o José. \\
3. Interrogativa sim/não & Seria ele a pessoa certa? \\
4. Construção optativa & Queira Deus que ele volte logo. \\
5. Construção imperativa & Vem pra Caixa você também! \\
6. Construção contrafactual diretiva & Chegasse você mais cedo, então! \\
7. Construção contrafactual condicional & Fosse você menos teimoso, tudo estaria bem. \\
8. Construção condicional correlativa & A data vai mudar, queira você ou não. \\
9. Construção completiva não-finita & Garantiu ser ele a pessoa certa. \\
\hline
\end{tabular}

O quadro acima é bastante heterogêneo. Em um primeiro corte, as duas primeiras construções se distinguem de todas as demais, pela seguinte razão: diferentemente dos padrões 1 e 2, as construções 3 a 9 apresentam restrições referentes à morfologia verbal e, em pelo menos dois casos, exibem ainda algum tipo de especificação lexical. Vejamos: a construção 3 especifica que o verbo deve vir no futuro (do pretérito ou do presente),

3 Essa lista é uma adaptação do quadro de Pinheiro (2009). 
a construção 4 exige o chamado modo optativo, a construção 5 demanda modo imperativo, as construções 6 e 7 requerem pretérito imperfeito do subjuntivo, a construção 8 pressupõe presente do subjuntivo e a construção 9 exige que o verbo esteja no infinitivo. Além disso, o padrão 8 especifica necessariamente a sequência "ou não", e é provável que o padrão 4 esteja representado na memória do falante sob a forma "Queira Deus que X". Isso significa que ele demanda não apenas um tempo/modo determinado, mas especificamente o verbo "querer" e o sujeito "Deus".

Nada disso, porém, se verifica nas construções 1 e 2. Aqui, não parece haver restrição ao tempo/modo verbal (Furou o pneu, Furava o pneu, Fura o pneu; Chegou o Carlos e o José, Vão chegar o Carlos e o José) ou qualquer especificação lexical prévia. O que essa breve discussão sugere é que as construções 1 e 2 são mais abertas, ao passo que as demais são mais fechadas ou restritivas, constituindo-se como padrões com maior grau de cristalização. Essa divisão inicial conduz a uma primeira delimitação do objeto de estudo: aqui, os usos mais cristalizados ou idiomáticos não serão investigados.

Isso, porém, não esgota a questão. Neste estudo, assumimos, como hipótese de trabalho, que as sentenças em 1 e 2 são instâncias de construções gramaticais distintas. A razão para isso está indicada no próprio nome sugerido para cada construção: elas apresentam estruturas informacionais diversas, na medida em que a porção do enunciado correspondente ao domínio do foco não é a mesma nos dois casos.

Na esteira de Lambrecht (1988; 1994; 2001a; 2001b), compreendemos o foco como uma categoria pragmática relacional: trata-se do "elemento da informação no qual a pressuposição e a asserção diferem uma da outra" (LAMBRECHT, 1994, p. 207; grifo no original). Em outras palavras, o domínio do foco corresponde à porção de uma proposição que não é pragmaticamente pressuposta, sendo, portanto, imprevisível e não-recuperável.
No que diz respeito aos usos 1 e 2 do quadro acima, é possível afirmar, ainda com base em Lambrecht (1988; 1994; 2001a; 2001b), que a construção 1 sinaliza foco sentencial, integrando assim a categoria das chamadas "all-new sentences" (LAMBRECHT, 1994; 2001), que se caracterizam pela ausência de conteúdo pressuposto. Na literatura sobre estrutura informacional, o foco sentencial costuma ser identificado por meio da pergunta “O que aconteceu?". Como o enunciado Furou o pneu é apropriado como resposta a essa pergunta, entende-se que ele manifesta foco sentencial.

Em contrapartida, o foco identificacional envolve conteúdo pressuposto. Um enunciado como Até agora, chegou o Carlos e o José é pragmaticamente mais apropriado como resposta a uma pergunta do tipo "Quem chegou?" do que como resposta à pergunta genérica “O que aconteceu?”. Isso significa que esse enunciado evoca uma informação pressuposta, qual seja, a informação de que alguém chegou. Ao mesmo tempo, sua função é identificar o referente desse "alguém". Em outras palavras, um enunciado como aquele que ilustra o padrão 2 é usado com o propósito de especificar quem, em meio ao conjunto de convidados, já chegou ao evento (em oposição a predicar o fato de que um evento de chegada ocorreu).

Neste artigo, então, tomaremos essa diferença como base para a postulação de duas construções gramaticais distintas (ainda que, muito provavelmente, relacionadas): uma construção cuja função é marcar foco sentencial e outra especializada na sinalização de foco identificacional. É essa distinção que permite delimitar o objeto do estudo: este artigo irá se restringir aos casos de foco sentencial. Estabelecida essa delimitação, passaremos a falar simplesmente em "construção VS". O leitor deverá ter em mente, porém, que estaremos tratando apenas de uma dentre as (possíveis) nove construções gramaticais de inversão do sujeito que fazem parte da gramática do português brasileiro. 


\section{Inversão do sujeito e semântica de frames: uma base conceptual para a construção VS}

Como já ficou dito, o objetivo central deste trabalho é demonstrar que a configuração verbo-sujeito está associada, de forma estável, a uma representação semântica específica. Para isso, passamos neste momento à descrição do polo semântico da construção VS.

Na esteira de uma semântica cognitivista, endossada pela maior parte dos modelos construcionistas de gramática (LANGACKER, 1987; 1991; 2008; GOLDBERG, 1995; 2006; 2013; CROFT, 2001), assumimos que a descrição do polo semântico de uma construção gramatical deve buscar responder, pelo menos, às seguintes questões: (i) qual é a cena conceptual evocada pela construção (propriedades ligadas ao nível do objeto conceptualizado, ou nível-O; cf. VERHAGEN, 2005)?; e (ii) de que maneira essa cena é construída ou conceptualizada pelo sujeito (propriedades ligadas ao nível do sujeito de conceptualização, ou nível-S; cf. VERHAGEN, 2007)?4. As seções 3.1 e 3.2 voltam-se, respectivamente, para cada uma dessas perguntas.

\subsection{Qual a cena conceptual evocada pela construção VS?}

Nesta seção, argumentaremos que a construção VS está associada a uma gestalt experiencial específica, a que iremos nos referir como Cena de Alocação da Atenção (CAA). O diagrama a seguir procura traduzir visualmente essa gestalt.

\footnotetext{
${ }^{4}$ Em particular, é a segunda questão que marca o caráter decididamente experiencialista (ou nãoobjetivista) da semântica cognitiva, já que sua ênfase recai não sobre o mundo em si mesmo, mas sobre a maneira como esse mundo é construído/conceptualizado pelo falante.
}

Figura 1 - Cena de Alocação da Atenção - 1ํㅡ versão

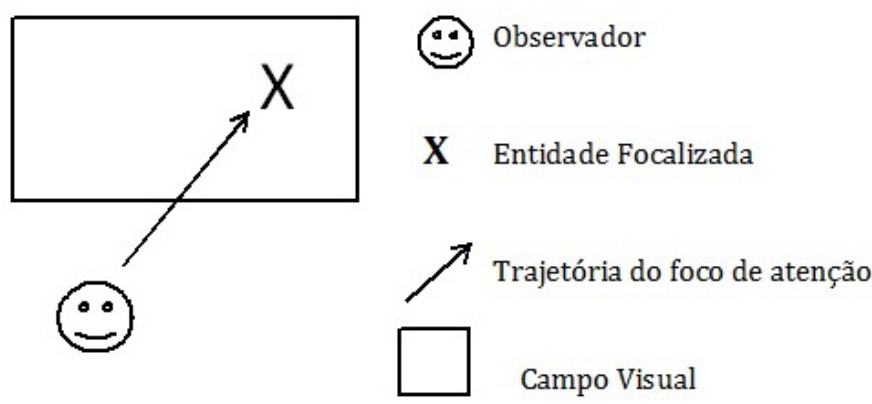

A CAA é um frame no sentido fillmoreano (FILLMORE, 1977; 1982): um sistema complexo de elementos no qual a compreensão de cada um deles demanda o acesso ao sistema como um todo. Especificamente, ela inclui os seguintes elementos conceptuais: o Observador, o Campo Visual (CV) e a Entidade Focalizada (EF). O Observador corresponde a um sujeito cognoscente in loco, ou seja, alguém que testemunha diretamente uma cena ou evento; o Campo Visual corresponde à totalidade do horizonte de consciência acessível ao Observador em um dado momento (incluindo seus estados internos); por fim, a Entidade Focalizada é o papel desempenhado pelo elemento que é focalizado pelo Observador ${ }^{5}$.

No conjunto, portanto, o que a CAA procura representar é uma situação dinâmica de (re)alocação da atenção, na qual se desenrola o seguinte processo: em um primeiro momento, uma dada entidade não está presente no CV do Observador; em um segundo momento, essa entidade ingressa no

${ }^{5}$ Como é praxe na tradição da semântica cognitiva, em especial nas vertentes de Leonard Talmy e Ronald Langacker recorremos ao domínio visual apenas como ponto de partida. Nesse sentido, nem sempre a palavra "Observador" será empregada em nua como ponto de partida. Nesse sentido, nem sempre a palavra Observador será enprega uma

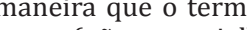

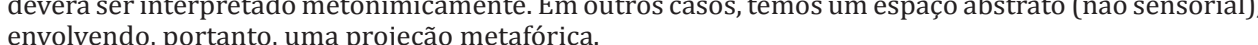


CV do Observador, que irá então alocar sobre ela seus recursos de atenção. Como resultado, essa entidade se torna uma EF. Vejamos:

(1) DI: aí esse meu amigo tava lá no camarim né’ e/ é:: esperando (+) aí daqui a pouco entrou esse tal de Marcelo (Corpus BBB 10)

No exemplo acima, o falante começa por estabelecer discursivamente um indivíduo - o referente do SN "esse meu amigo" - que mais tarde desempenhará o papel de Observador. Observe-se que, em um primeiro momento, o personagem referido como "esse tal de Marcelo", que corresponde à EF, não está presente no CV do "amigo" do narrador. Na sequência da narrativa, contudo, ele adentra o camarim, irrompendo no horizonte perceptual do Observador, que passa a alocar sobre ele seus recursos de atenção.

Note-se que o mesmo se verifica nos casos em que o referente do sujeito não é conhecido por nenhum dos interlocutores:

\section{(2) L: que/ caiu alguma coisa (Corpus BBB 10)}

(3) minha mãe costumava ir numa rua de cima ali... porque nós temos muitos conhecidos... eu já morei ali... sabe? foi ela e meu irmão... aí ela me contou... que chegando lá... eles ficaram conversando com... com... o pessoal de lá... daqui a pouco começou a correr gente lá pra esquina... (Corpus $D \& G$ Narrativa recontada - Rio de Janeiro 2)

O enunciado em (2), produzido pela participante Lia do BBB 10, evoca uma cena na qual um Observador (que aqui coincide com a própria falante) tem sua atenção direcionada para uma entidade (representada pelo SN "alguma coisa") graças ao som produzido pela sua queda. Note-se que, embora essa entidade seja desconhecida, trata-se de uma entidade específica (ou, talvez, algumas entidades específicas). Em (3), diferentemente, o sujeito tem referência genérica (um conjunto indeterminado de pessoas). Ainda assim, não é difícil constatar que a cena evocada se conforma ao esquema da CAA: a corrida "lá pra esquina" atrai a atenção da mãe e do irmão do falante, que desempenham então o papel de Observadores ${ }^{6}$.

\subsection{De que maneira a cena conceptual evocada pela construção VS é construída/conceptualizada pelo falante?}

A questão da construção/conceptualização é tratada pela semântica cognitiva langackeriana (LANGACKER, 1987; 1991; 2008) à luz do conceito de construal. Esse conceito busca capturar o fato de que uma mesma cena objetiva pode ser construída pelo falante de diferentes maneiras. Nos termos de Langacker (2008), o construal pode envolver quatro dimensões: especificidade, foco, proeminência e perspectiva. Aqui, argumentaremos que as dimensões relevantes para a construção VS são duas: proeminência e

${ }^{6}$ Um parecerista anônimo levantou a interessante questão de como lidar com sentenças do tipo "Morre todo policial que desafia os traficantes". Acreditamos que esse uso exibe foco identificacional, sendo, portanto, análogo ao de enunciados como "Do meu lado sentou o João" e "Primeiro falou o presidente" Se estivermos corretos, isso significa que se trata de uma manifestação da construção 2 do Quadro 2 - e não da construção 1, eleita como objeto de estudo deste trabalho. Por outro lado, uma questão relevante diz respeito à possibilidade de abranger as construções $1 \mathrm{e} 2 \mathrm{em}$ um tratamento unificado. Em termos construcionistas, isso significaria postular uma construção VS mais geral - isto é, mais abstrata e, portanto, com menos especificações semântico-pragmáticas - posicionada acima das construções 1 e 2 em uma rede construcional taxonômica. Do ponto de vista pragmático, essa construção teria foco nãocanônico (GOLDBERG, 2006), ou seja, estrutura de foco diferente de tópico-comentário. Essa suposição é plausível, dado que, como mostra Lambrecht (2001), muitas línguas colapsam as duas estruturas de foco não-canônico (isto é, foco sentencial e foco identificacional) em uma mesma codificação formal foco não-canônico (isto é, foco sentencial e foco identificacional) em uma mesma codificação formal a possibilidade de descrever ambas as construções por meio de uma CAA, deixando apenas nãoa possibilidade de descrever ambas as construções por meio de uma CAA, deixando apenas não-
marcada a direcionalidade do início do processo de focalizacãa da atenção (da EF para o Observador marcada a direcionalidade do início do processo de focalização da atenção (da EF para o Observado ou vice-versa). Assim, na construção 1, teríamos a EF atraindo a atenção do Observador, ao passo que a construção 2 evocaria uma cena na qual o Observador busca ativamente a EF. Interessantemente, essas duas possibilidades correspondem aos dois modos de alocação da atenção tipicamente descritos em psicologia cognitiva: respectivamente, espontânea/exógena ("stimulus-directed") e voluntária/ endógena ("goal-directed"). Essa proposta para a construção 2 pode ser mais facilmente apreciada no casos de enunciados que expressam eventos concretos, como "Do meu lado sentou o João". No entanto, não é difícil, por meio dos instrumentos da semântica cognitiva, estendê-la para locativos abstratos sejam elas temporais ou de outra natureza. A rigor, é precisamente isso que Chen (2003) propõe para português brasileiro (cf. Quadro 2 acima), e que pode ser facilmente traduzido nos termos da CAA. 
perspectiva. As seções 3.2.1 e 3.2.2 tratam, respectivamente, de cada uma delas.

\subsubsection{CAA e proeminência}

A categoria de proeminência diz respeito ao grau de saliência cognitiva dos diferentes elementos pertencentes a uma dada estrutura conceptual. A ideia básica é a seguinte: embora evoquem frames complexos, as construções gramaticais apenas atribuem um grau especial de proeminência a uma subparte do frame evocado (FILLMORE, 1977; 1982; LANGACKER, 1987; 1991; 2008). Nos termos da Gramática Cognitiva langackeriana (1987; 1991; 2008), o sistema complexo de elementos é chamado de base ("base"), ao passo que sua porção particularmente saliente corresponde ao perfil ("profile"). Por isso, diz-se que, no interior de uma dada base, apenas um subconjunto dos elementos é perfilado ("profiled").

Na esteira de Goldberg (1995), assumimos que os elementos perfilados de uma construção gramatical são aqueles que estão previstos em sua representação sintática - e deverão ser, portanto, realizados fonologicamente. No caso da construção VS, há apenas um slot sintático disponível: aquele correspondente ao SN sujeito. Como se vê em (1) a (3), esse slot está associado à EF da CAA. Isso significa que os demais elementos da CAA não são linguisticamente representados pela construção, de maneira que poderão não ser expressos fonologicamente. Quando isso acontece, eles devem ser recuperados discursivamente, interpretados deiticamente ou inferidos a partir do conhecimento de mundo do ouvinte/leitor.

Vejamos, a título de exemplo, a sentença VS de (1), que está destacada em negrito. Embora ela evoque uma situação na qual um Observador se depara com uma entidade que ingressa em seu CV, nem o Observador nem o CV são linguisticamente codificados. Nesse caso, o Observador pode ser recuperado discursivamente: trata-se, como já notamos, do referente do SN "o meu colega". Ao mesmo tempo, o CV é construído a partir do conhecimento de mundo do leitor/ouvinte: trata-se da totalidade do horizonte de consciência que podemos atribuir ao Observador naquele ponto da narrativa.

O que se constata aqui é que a sentença VS em (1) evoca muito mais informações do que ela de fato expressa ${ }^{7}$ : ela expressa diretamente um evento de movimento (a entrada do Marcelo), mas evoca implicitamente uma experiência de percepção acerca desse evento de movimento. Neste artigo, argumentamos que essa situação se verifica sistematicamente em sentenças com sujeito pós-verbal, podendo, portanto, ser direta e convencionalmente associada à própria construção sintática verbo-sujeito. Dessa maneira, diremos que a construção VS, embora predique uma $\mathrm{CAA}^{8}$, perfila apenas um elemento conceptual no interior desse frame: a EF. À luz dessa proposta, a Figura 1 acima pode ser ligeiramente modificada, da seguinte maneira:

Figura 2 - Cena de Alocação da Atenção - 2ª versão

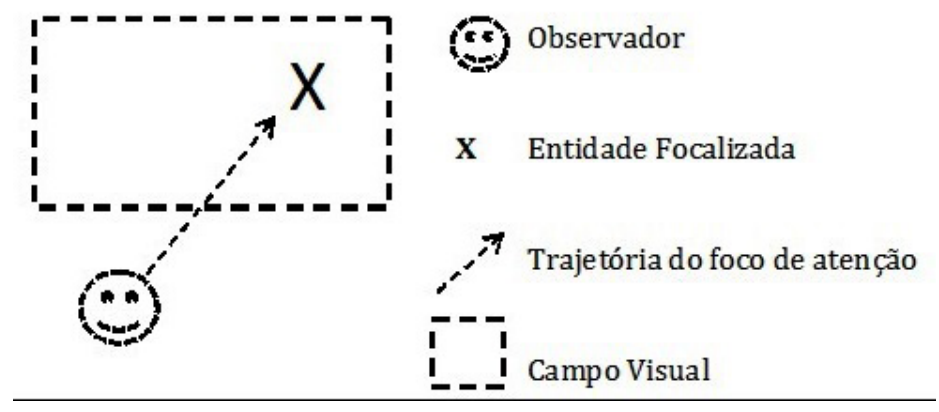

Na figura acima, note-se que apenas um elemento da CAA aparece representado com linhas cheias: o "X", correspondente à EF. Por outro lado,

7 Essa posição certamente não deve surpreender: ela apenas confirma a tese, cara à tradição da Linguística Cognitiva, de que "significados são relativizados a cenas" (FILLMORE, 1977).

8 Na Gramática Cognitiva (LANGACKER, 1987; 1991; 2008), o verbo "predicar" é usado para fazer referência à totalidade da cena evocada por uma construção gramatical. Ele se opõe ao termo "designar", usado para indicar a referência, especificamente, à parte perfilada de uma predicação. 
tanto o Observador quanto o CV são representados com linhas pontilhadas. Essa diferença de representação busca marcar visualmente a distinção entre elementos perfilados e elementos conceptualmente pressupostos.

Até este momento, portanto, sugerimos que (i) a construção VS evoca uma CAA e (ii) a construção VS perfila apenas um elemento da CAA: a EF. A comparação entre os exemplos abaixo ilustra a importância dessa caracterização.

(4) a. F: Di, seu chapéu tá no banquinho vermelho (Corpus BBB 10)

b. ?? Di, tá seu chapéu no banquinho vermelho.

c. Aí, quando eu olho, tá seu chapéu no banquinho vermelho.

Enquanto (4a) é um dado efetivamente atestado, os exemplos (4b) e (4c) são adaptações da sentença original, com o deslocamento do sujeito para a posição pós-verbal. Como se vê em (4b), a simples posposição do sujeito de (4a), sem quaisquer outras alterações, reduz sensivelmente a naturalidade do enunciado. Por outro lado, o acréscimo levado a cabo em (4c), com a inserção da sequência "quando eu olho", parece resgatar sua aceitabilidade. Como explicar esses fatos?

Nossa explicação segue as seguintes linhas: como a construção VS está convencionalmente associada à CAA, é necessário que o referente do seu sujeito possa ser interpretado como uma EF (isto é, como uma entidade que ingressa no Campo Visual de um Observador in loco). A sentença (4b), no entanto, parece não descrever uma experiência de percepção, mas tãosomente um cenário de contenção de uma entidade (o "chapéu") em um espaço (a região do "banquinho vermelho"). Em contrapartida, o contexto discursivo mínimo acrescido em (4c) sugere a existência de um Observador (representado por "eu") que, a certa altura, se depara com uma entidade (representada por "seu chapéu") em seu CV. Por isso, é possível em (4c), mas não em (4b), construir o referente do sujeito como EF - o que explica a pouca naturalidade deste último.

Como se vê, a distinção entre (4a) e (4c) só se torna visível quando se insiste na necessidade de observar não apenas o cenário objetivamente expresso por uma construção gramatical, mas a totalidade do frame evocado por ela - aí incluídas as informações conceptualmente pressupostas. É esse tipo de análise que nos permitirá detectar a seguinte diferença: enquanto (4a) comunica que uma entidade está locada em um espaço, a sentença em negrito em (4c) comunica que um Observador constatou in loco que uma entidade está locada em um espaço. Por um lado, apenas a segunda parte desse conteúdo (a locação propriamente dita) é conceptualmente saliente o restante do conteúdo semântico se mantém "submerso", correspondendo à base ou background conceptual da predicação. Por outro lado, é esse conteúdo "submerso" que se mostra sintaticamente relevante, já que é ele que permite explicar os fatos distribucionais evidenciados pelos exemplos em (4).

\subsubsection{CAA e perspectiva}

A segunda dimensão de construal relevante para a nossa proposta diz respeito à categoria de perspectiva. Resumidamente, trata-se de estabelecer a partir de que ponto de vista a CAA é conceptualizada. Naturalmente, um evento de conceptualização pressupõe a existência de um conceptualizador - vale dizer, um sujeito dotado de mente e, portanto, capaz de apreender e interpretar a realidade a que tem acesso. A pergunta que se coloca, portanto, é a seguinte: quem é e onde se situa o sujeito que conceptualiza o evento expresso pela sentença VS?

Note-se que a própria CAA disponibiliza um sujeito cognoscente com essas características: o Observador. No entanto, cabe lembrar que toda enunciação linguística pressupõe um ground comunicativo - isto é, uma 
situação interacional concreta onde se localiza um falante e pelo menos um ouvinte, ainda que virtual (LANGACKER, 2008; FERRARI; SWEETSER, 2012). Esse falante, claro, também é um sujeito cognoscente capaz de impor sua própria perspectiva sobre os fatos observados (DANCYGIER, 2012). Isso significa, em suma, que o falante pode construir o evento segundo seu próprio ponto de vista ou pode, alternativamente, "terceirizar" o ponto de vista, construindo-o sob a ótica de alguém que o tenha testemunhado diretamente (isto é, um Observador).

Aqui, argumentaremos que a construção VS não apenas evoca a conceptualização de uma CAA, mas o faz sob o ponto de vista do Observador. Isso significa que, ao optar por codificar o evento com ordem linear verbosujeito, o falante escolhe construí-lo segundo a perspectiva de um indivíduo que participou diretamente da situação narrada, atuando como "testemunha ocular". Se essa análise estiver correta, a Figura 1 pode ser modificada novamente, da seguinte maneira:

Figura 3 - Cena de Alocação da Atenção - 3a versão

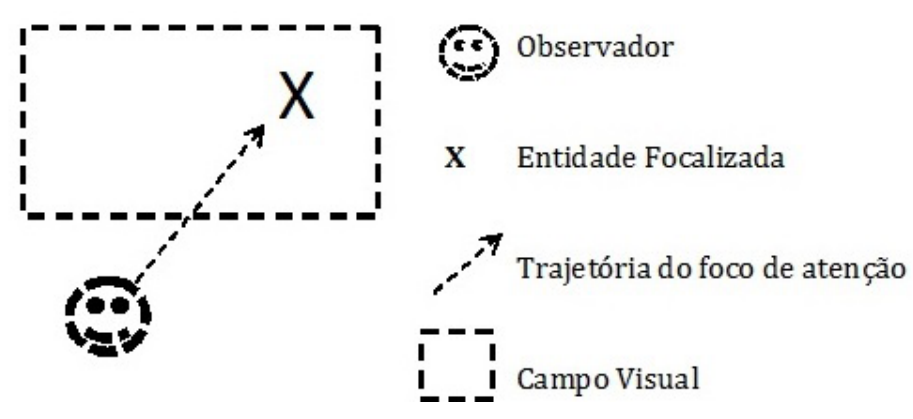

Assim como a Figura 2, esse diagrama também captura, por meio das linhas cheias e pontilhadas, a diferença entre elementos perfilados e pressupostos. Mas, para além disso, a linha mais espessa na representação do
Observador indica ainda que o evento narrado é construído sob a perspectiva desse sujeito cognoscente in loco.

Evidência em favor dessa hipótese vem, sobretudo, da seguinte constatação: nos casos em que o contexto pragmático impede a atribuição do ponto de vista ao Observador, a inversão do sujeito parece francamente inaceitável. Uma situação desse tipo pode ser vista nos exemplos abaixo, ambos extraídos do corpus D\&G.

(5) o Alexandre pegou o carro dele e foi... comprar cerveja... aí estava descendo pela Conde de Bonfim... né? e ia dobrar... numa rua à esquerda... que era contramão ((riso)) pra ir no/ na... na padaria que estava aberto lá pra comprar cerveja... no bar que estava aberto pra comprar cerveja... aí ele... pô... ligou a seta... reduziu... quando ele virou pra esquerda pra cruzar a Conde de Bonfim... vinha um táxi... ((interrupção de colega de trabalho)) vinha um táxi correndo pra caramba... e bateu... na porta dele... do lado dele assim... acabou o carro... pô... ele se machucou na cara... cortou a cara... entrou vidro dentro do olho dele... mas não chegou a se... a se ferir gravemente não... foi só assim leve... né? e pô:: o mais engraçado é que ele saltou do carro... pô... putão... e o motorista do táxi tranquilíssimo... ligando já pra::/ pegou o rádio lá que tem no táxi e ligando lá pra Central... pediu reboque e não sei o quê... não deu nem atenção pra ele... aí pararam ((riso)) parou uma porção de tá::xi... aí os caras do táxi começaram a arrumar confusão... com ele... pô... ele falou que... os caras do táxi falando pra ele assim "pô... ninguém vai pagar teu prejuízo mesmo... sai fora" ((riso)) e::... e não pagaram mesmo não... o cara/ veio a polícia... registraram a ocorrência... o próprio policial falou que não adiantava nada [...] (Corpus D \& G)

(6) E: mas ele também estava errado... né? entrar na contramão...

I: não... ele estava errado... mas o táxi veio cortando pela contramão também... o cara do táxi que estava mais errado do que ele ainda... e tanto o policial falou que o cara/ ele tinha toda chance de ganhar no tribunal... (Corpus D \& G) 
O uso VS em (5) está inserido em uma narrativa mais ampla, protagonizada pelo motorista Alexandre. É fácil notar que toda a sequência de acontecimentos é apresentada sob a perspectiva desse personagem: o ouvinte/leitor só tem acesso a novos cenários ou paisagens na medida em que o campo visual do Alexandre vai se alterando. Em particular, a sequência "quando ele virou pra esquerda pra cruzar a Conde de Bonfim" sugere fortemente que o ouvinte/leitor deve se colocar "no lugar" do personagem, enxergando o acontecimento subsequente "pelos seus olhos". Nesse sentido, o emprego, na sequência da narrativa, da ordem linear verbo-sujeito está em consonância com a hipótese que defendemos aqui.

Ao final da narrativa, contudo, o entrevistador busca evidenciar a fragilidade da tese implícita na fala do informante, segundo a qual o motorista Alexandre não teria tido reponsabilidade pelo acidente. Para isso, ele chama atenção para o fato de que o Alexandre havia deliberadamente entrado na contramão. É nesse momento que o informante enuncia a sentença SV destacada em (6).

O dado fundamental é que a inversão do sujeito parece, no mínimo, pouco natural nesse contexto. Isso fica claro no exemplo abaixo, um dado inventado no qual se busca manipular artificialmente a sentença em negrito de (6):

(7) não... ele estava errado... \# mas veio o táxi cortando pela contramão também...

Como explicar a estranheza de (7)? Nossa proposta é a de que a opção pela ordem VS é contraditória com certas pistas linguísticas e pragmáticas disponíveis na mesma sequência textual ${ }^{9}$. Pragmaticamente, observa-se que

\footnotetext{
9 Um parecerista anônimo questionou a qualificação da ordem VS, neste contexto, como "contraditória". Com esse adjetivo, não gostaríamos de sugerir que a inversão do sujeito é aqui decididamente impossível analisamos a seguir. 0 term "contraditóra" embute tão-somente a sugestão de que existe umentito
}

a sentença SV em (6) não se insere em um texto narrativo, mas em uma argumentação: ela está a serviço de sustentar a tese do informante (segundo a qual a responsabilidade pelo acidente caberia ao taxista), no interior do embate argumentativo que se desenrola naquele momento entre ele e o entrevistador. Este ponto, portanto, é crucial para a nossa análise: enquanto a sentença VS de (5) é proferida em uma situação interacional de relato de uma história, a sentença SV de (6) é proferida em uma situação na qual o informante e o entrevistador protagonizam um (leve) embate argumentativo.

Linguisticamente, cabe notar a presença do conectivo "mas" e do focalizador "também". Ambos são elementos que atuam diretamente no gerenciamento da negociação intersubjetiva: enquanto o conectivo "mas" marca a oposição à tese expressa pelo entrevistador no turno de fala anterior, o item "também" focaliza uma informação presente na mesma fala do entrevistador (a informação sobre "entrar na contramão").

Somados, esses fatores fornecem fortes evidências de que, no contexto de (6), o ouvinte/leitor deve construir a informação de vinda do carro pela contramão como um argumento a que o falante está recorrendo naquele momento da interação para desacreditar a tese do seu interlocutor (e não como uma experiência vivenciada por um terceiro sujeito em algum momento do passado). Tecnicamente, essa conclusão pode ser formulada assim: as pistas pragmáticas e linguísticas presentes no excerto acima convidam o ouvinte/leitor a construir o evento de vinda do carro, no contexto de (6), sob o ponto de vista do próprio falante (o informante que participa da entrevista para composição do corpus) e não sob o ponto de vista do Observador (o motorista Alexandre, personagem da narrativa).

entre diferentes pistas linguísticas presentes na mesma sequência textual. A literatura mostra que esse conflito (ou contradição) não é necessariamente irreconciliável (MICHAELIS, 2004. NIKIFORIDOU, 2013) emora neste caso ele pareça conduzir a um uso menos aceitável, assim como em muitos ou tros 2013), en GOLDBERG, 2011) 
Ora, se de fato a ordem VS está associada ao ponto de vista do Observador, o que se espera é que a inversão do sujeito seja pouco aceitável em uma situação como a de (6), na qual a responsabilidade pela construção do evento é atribuída diretamente ao falante (e não ao Observador). A pouca naturalidade de (7) pode, portanto, ser explicada como segue: em uma situação no qual o ouvinte/leitor tem fortes motivos para construir uma determinada informação sob a perspectiva do falante, a codificação de (7) fornece uma pista contraditória, indicando, pela via da própria ordem sintática linear, que o evento deve ser conceptualizado sob a ótica do Observador. Aqui, portanto, é o conflito entre a pista fornecida pela construção VS e o conjunto de pistas linguísticas e pragmáticas fornecidas anteriormente que produz a inaceitabilidade de (7).

\section{Interação verbo-construção}

Alguns estudos têm identificado uma correlação entre inacusatividade verbal e inversão do sujeito (FIGUEIREDO SILVA, 1996; COELHO, 2000). Ao mesmo tempo, parece bem estabelecido que a ordem VS não é exclusividade desses verbos, podendo se manifestar ainda com verbos inergativos e mesmo transitivos (PILATI, 2002). A nosso ver, uma abordagem satisfatória para a inversão do sujeito deve ser capaz de explicar, ao mesmo tempo, (i) por que a inversão ocorre tipicamente com verbos inacusativos e (ii) por que a inversão não ocorre apenas com verbos inacusativos ${ }^{10}$.

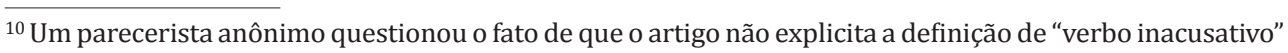
com a qual trabalha. Isso é porque, a rigor, a proposta apresentada aqui não faz uso da noção de inacusatividade - e, de todo modo, a categoria "verbo inacusativo" não tem qualquer papel em uma abordagem não-projecionista como aquela que advogamos aqui. Como se verá ao longo desta seção, o que propomos, de fato, é contrapor as explicações sintáticas, que associam a inversão do sujeito à inacusatividade verbal a uma abordagem de natureza semântico-conceptual, segundo a qual a correlação estatística entre verbos inacusativos e sentenças VS não é mais que um subproduto de uma especificação semântica mais básica, que pode ser capturada por meio da CAA (e esta é precisamente a razão pela qual tal correlação pode ser vio-
Nossa própria hipótese é a de que diferentes tipos de verbos (isto é, verbos pertencentes a diferentes categorias sintáticas e classes semânticas) podem instanciar a construção VS, desde que o referente do sujeito sintático possa ser construído como Entidade Focalizada (ou, dito de outra maneira, desde que uma Cena de Alocação de Atenção possa ser evocada). Essa hipótese é compatível com o fato de que verbos inacusativos tipicamente licenciam a posposição. Basta pensar que ao argumento desses verbos se atribui em geral o papel de tema/paciente (em vez de agente ou experienciador). Ora, como esses papéis são normalmente associados a propriedades como locação/existência, mudança de lugar e mudança de estado (FILLMORE, 1968; JACKENDOFF, 1990; SAEED, 2003), elementos que apresentem esses papéis são candidatos naturais a figurarem como participantes de um evento de aparição - ou, em outras palavras, em uma Cena de Alocação de Atenção.

Consideremos, por exemplo, a proposta de Duarte (2003), para quem a "família de construções inacusativas" inclui quatro grupos de verbos: verbos de mudança de estado (como "nascer" ou "explodir"), verbos de movimento (como "cair" ou "chegar"), verbos de existência (como "existir" ou mesmo "faltar", que denota não-existência) e verbos de aparição (como "aparecer" e "surgir"). Não é difícil verificar que verbos pertencentes a todas essas classes são muito naturalmente compatíveis com a CAA. Mais adiante (a partir de 5.1), desenvolvemos mais detidamente esse ponto e apresentamos exemplos reais, mas consideremos agora alguns dos verbos mencionados acima a título de exemplo.

Se alguém ouve um estrondo e então profere um enunciado como "Explodiu uma bomba", o que se tem é uma situação na qual o falante, no papel de Observador, direciona seus recursos de atenção para uma bomba que, até aquele momento, não estava presente no seu horizonte perceptual ${ }^{11}$.

${ }^{11}$ Mais acima, dissemos que os nomes com os quais batizamos os elementos da CAA deverão, em alguns casos, ser entendidos figurativamente - seja metafórica ou metonimicam metonímica, já que se trata mais propriamente de um "Campo Auditivo" do que de um "Campo Visual". 
De maneira semelhante, um enunciado como "Caiu uma bolinha de papel na cabeça do Serra" evoca uma cena na qual uma entidade (a "bolinha de papel") passa a estar presente na consciência imediata de um sujeito cognoscente (graças, neste caso, à sua queda). Algo semelhante ocorre em um enunciado como "Está faltando sal na comida", em que o Observador tem sua atenção direcionada para o sal precisamente em função da sua ausência. Por fim, um uso como "Apareceu um fantasma bem na minha frente" parece ser a própria tradução da CAA: uma entidade (o fantasma) ingressa no Campo Visual de um Observador (que aqui coincide com o falante), atraindo sua atenção.

O problema de se estabelecer uma relação direta entre inacusatividade e ordem VS são dois: em primeiro lugar, não é simples explicar por que alguns verbos inacusativos são mais resistentes à inversão do que outros (por exemplo, "estar" e "morar" são mais resistentes que "aparecer"); em segundo lugar, e principalmente, verbos não-inacusativos também podem licenciar a inversão (veremos abaixo exemplos reais com "correr" e "bater"). Nenhum desses dois problemas, porém, emerge na presente proposta. Por um lado, é natural, à luz da nossa proposta, que "aparecer" licencie a inversão com mais facilidade que "estar", já que o primeiro, mas não o segundo, envolve necessariamente um Observador: para que um evento de aparecimento seja qualificado como tal, é necessário que alguém o presencie, o que não ocorre com uma cena simples de locação como a que costuma ser designada pelo verbo "estar". Por outro lado, nossa proposta não impede, a priori, que verbos inergativos ou transitivos instanciem a construção VS, desde que eles cumpram a condição fundamental de que o referente dos seus sujeitos possa ser construído como EF. Este é, por exemplo, o caso de "gritar" em um exemplo como "aí daqui a pouco grita um maluco lá do outro lado"12: aqui,

${ }^{12}$ A sequência completa, retirada do corpus BBB 10, é a seguinte: eu tava lá no:: tipo:: andando na rua
né' na:: ali na Barra' aí daqui a pouco grita um maluco lá do outro lado. Por limitações de espaço, não poderemos analisá-la mais detidamente aqui, mas não é difícil verificar que ela se conforma à CAA. verifica-se que o grito atrai a atenção do Observador, que passa a então a incluir uma representação do "gritador" em seu horizonte de consciência (vale dizer, seu CV).

Nas próximas seções, discutimos exemplos reais em que verbos de diferentes classes semânticas e sintáticas exibem sujeito pós-verbal. Exclusivamente por razões didáticas, esses verbos foram agrupados em função de afinidades semânticas, mas o leitor deve ter em mente que essa divisão não é crucial para nossa proposta - em vez disso, nossa tese é a de que todos esses casos se conformam à generalização da CAA.

\subsection{Verbos de aparição}

Como já comentamos, verbos de aparição podem ser facilmente instanciados na construção VS em função da compatibilidade entre sua estrutura semântica e a CAA. Afinal, tanto os verbos de aparição quanto a CAA representam um evento de aparecimento, de maneira que o referente do sujeito desses verbos é facilmente construído ou enquadrado como uma $\mathrm{EF}$, como se vê abaixo.

(8) de repente... aparece do... dois garotos... que ro/ queriam roubar o relógio dele... (Corpus $D \& G$ )

No exemplo acima, o surgimento dos "dois garotos" captura atenção do Observador, papel desempenhado aqui pelo personagem anteriormente introduzido na narrativa. O referente de "dois garotos" desempenha, portanto, o papel de EF.

\subsection{Verbos locativos}

Um verbo locativo como "estar" não denota, em si mesmo, uma experiência de alocação da atenção. Isso explica por que ele parece mais 
resistente à inversão do sujeito do que os verbos de aparição. Contudo, dado o contexto discursivo apropriado, o verbo "estar" pode, sim, amoldarse à construção VS. Como se vê abaixo, esse "contexto apropriado" inclui a disponibilização discursiva de um Observador ${ }^{13}$ :

(9) é como se ele visse... ele olhasse pra um lado... olhasse pra outro e visse tá aqui a solu/ a solução... tá nas minhas mãos... (Corpus D\&G)

(10) o caminhão foi andando uns duzentos metros... e ela está ali embaixo naquele desespero todo e sem poder... tá entendendo? fazer nada... porque... o motorista não estava vendo... só quando o pessoal começou a gritar mesmo... que:: ele só/ foi escutar e parou o caminhão... quando ele parou o caminhão... estava a rua toda cheia de sangue... (Corpus $D \& G$ )

Em (9), a sentença VS não predica simplesmente a presença da "solução" no espaço designado pelo dêitico "aqui" - e sim o aparecimento dessa solução diante de um Observador (representado pelo pronome "ele"). Analogamente, em (10), o enunciado em negrito não predica apenas um cenário em que a rua está cheia de sangue, mas reproduz, de maneira especialmente vívida e dramática, a percepção de um sujeito in loco (o motorista do caminhão) em relação a esse cenário. Nesse sentido, ambas as sentenças destacadas predicam a CAA.

\subsection{Verbos de movimento}

Assim como verbos de aparição e locativos, verbos de movimento instanciam facilmente o padrão VS. Isso ocorre pela seguinte razão:

\footnotetext{
${ }^{13}$ Como mostram os exemplos, optamos por agrupar, sob o rótulo de "verbo locativo estativo", duas acepç̃es distintas do verbo "estar": seu uso propriamente locativo, ilustrado em (9), e seu uso como verbo "de ligação", ilustrado em (10). É a metáfora EsTADOs SÃo LUGARES (LAKOFF; JOHNSON, 1980) que permite estabelecer esse agrupamento.
}

embora esses verbos não prediquem inerentemente o surgimento de uma entidade, o movimento designado por eles pode produzir, como resultado, $\mathrm{o}$ aparecimento da entidade no CV de um Observador, permitindo que ela seja construída como EF. É essa possibilidade que torna os verbos de movimento altamente compatíveis com a construção VS.

Um exemplo dessa compatibilidade pode ser visto abaixo:

\section{(11) S: bi entrou uma mariposa desse tamanho no: na cozinha $(+)$ começou a voar' não consegui nem comer direito (Corpus BBB 10)}

Em (11), o deslocamento da mariposa acaba por fazê-la ingressar no horizonte visual de um Observador, que neste caso coincide com o falante. Por essa razão, a mariposa desempenha o papel de EF. Aqui, portanto, vemos que o aparecimento da $\mathrm{EF}$ no $\mathrm{CV}$ do Observador é resultado do seu deslocamento.

\subsection{Verbos de mudança de estado}

Também os verbos de mudança de estado podem instanciar a construção VS. Isso é esperado, na medida em que a semântica desses verbos é compatível com a CAA. Tal compatibilidade segue a seguinte lógica: assim como o deslocamento de uma entidade pode produzir, como resultado, o seu aparecimento no CV de um Observador, o mesmo se dá com a mudança de estado. Em outras palavras, é comum que passemos a atentar para uma determinada entidade em função de uma alteração no seu estado. Vejamos:

(12) na volta / bom... foi tudo tranquilo... almoçamos lá... quando a gente está voltando... começa a chover assim... torrencialmente... e fura o pneu... (Corpus $D \& G$ ) 
Em (12), a cena designada pela sentença VS é construída sob a perspectiva de duas amigas que estão dentro do carro; são elas que desempenham, portanto, o papel de Observador. Note-se que, num primeiro momento, o pneu não faz parte da representação de mundo correntemente ativada para elas. A sentença VS, por outro lado, traduz o momento em que o pneu se insere no CV das Observadoras, tornando-se "visível" para elas graças ao fato de ter furado. Aqui, portanto, ocorre algo semelhante ao que vimos no exemplo (11): o evento denotado pelo verbo (o estouro do pneu) corresponde ao meio que produz como resultado o evento de aparecimento e (re)alocação da atenção.

\subsection{Verbos sensoriais}

O mecanismo que permite a compatibilização de verbos sensoriais com o padrão VS é fundamentalmente idêntico àquele que verificamos para os verbos de movimento e mudança de estado: também aqui, o verbo designa o meio que produzirá, como resultado, o aparecimento da EF e a (re)alocação da atenção do Observador. Vejamos.

(13) aí a gente::... caiu sentada... mas a gente não se machucou... ficou doendo... aí... aí... bateu o sinal... aí a gente foi formar... (Corpus D\&G - Narrativa de experiência pessoal - Rio de Janeiro 1)

(14) C: não foi engraçado pra caRAlho' ouve essa' eu tava lá me arrumando né" aí daqui a pouco toca o telefone' aí é a Mônica' Cadu vem me buscar" (Corpus BBB 10)

Em (13), o som produzido pelo sinal (EF) captura a atenção dos personagens referidos por meio do pronome "a gente" (que desempenham, então, o papel de Observador). Em (14), semelhantemente, temos a seguinte situação: o falante está se arrumando quando, a certa altura, é surpreendido pelo toque do telefone, voltando assim sua atenção para ele. Aqui, portanto, o falante desempenha o papel de Observador ao passo que o telefone funciona como EF.

\subsection{Verbos de ação}

Embora não seja comum, é fato que verbos de ação podem, em alguns casos, exibir sujeito posposto. E, o mais interessante, esses casos não são fundamentalmente diferentes daqueles que envolvem verbos de movimento, de mudança de estado e de percepção sensorial. Isso porque, também aqui o verbo denota o meio que produz como resultado o aparecimento da EF no CV do Observador, como se vê abaixo.

(15) chegando lá... eles ficaram conversando com... com... o pessoal de lá... daqui a pouco começou a correr gente lá pra esquina... correr gente assim... correr bastante gente... (Corpus $D \& G$ )

Aqui, a narrativa é apresentada sob o ponto de vista dos personagens referidos como "eles". Num primeiro momento, marcado pela sequência eles ficaram conversando com... com... o pessoal de lá..., há uma situação de estabilidade. Num segundo momento, introduzido pela expressão "daqui a pouco", o olhar dos personagens é subitamente atraído pela movimentação dos passantes. Neste caso, então, a cena designada pela sentença VS - a correria das pessoas "lá pra esquina" - é construída como uma experiência de percepção vivenciado por esses dois personagens (os Observadores).

Um exemplo análogo aparece abaixo:

(16) então eu fiquei chorando em casa... não fui pra festa... aí ela foi... só que aí bateu uma amiga minha lá na porta de casa me chamando pra ir... (Corpus $D \& G$ ) 
A análise de (15) se aplica a este exemplo. Aqui, mais do que representar a ação realizada pela "amiga minha" (isto é, o ato de transferência de energia dessa amiga para a porta), a sentença predica o resultado dessa ação: o ingresso do referente do sujeito no CV do Observador (o falante). Tanto assim que, neste contexto, a informante poderia ter optado por formular a sentença da seguinte maneira: só que aí apareceu uma amiga lá em casa. Não estamos propondo, é claro, que essa paráfrase é perfeitamente equivalente ao uso original; o objetivo aqui é apenas evidenciar o fato de que, ao fim e ao cabo, o enunciado em destaque representa, primariamente, uma experiência de percepção in loco - e não uma ação prototípica de transferência de energia.

\section{Considerações finais}

Neste trabalho, propusemo-nos a descrever a ordem VS do PB como uma construção gramatical - ou seja, uma unidade simbólica que reúne informações de forma e significado. Sob essa ótica, buscamos mostrar que o esquema sintático abstrato VERBo-SUJEITO está direta e inerentemente vinculado a uma especificação semântica. Tal semântica, no entanto, não foi apreendida em termos de papéis temáticos ou classes semânticas, mas a partir de uma gestalt experiencial específica: a Cena de Alocação da Atenção, descrita na seção 4 em relação a suas propriedades de nível-O (4.1) e de nível -S, ligado ao construal (4.2) ${ }^{14}$. Ao mesmo tempo, buscamos mostrar

\footnotetext{
${ }^{14}$ Um parecerista anônimo levantou a questão da possível universalidade da descrição proposta. Tratase de uma questão interessantíssima, de maneira que lamentamos não ter espaço para desenvolvê-la aqui com o aprofundamento devido. Por isso, limitamo-nos a algumas observações breves. Em primeiro lugar, em uma perspectiva construcionista, de matriz funcional-cognitiva, não existe a suposição de que o conhecimento gramatical seja em parte inato e universal. Nesse sentido, não faz parte desse programa de pesquisa a busca por prinć́pios ou mecanismos - ou, em outros termos, construç̃̃es -que possama estar presa tes em todas ou na maioria das línos - ous evam as construções são particulares a cada língua (CROFT, 2001). Por outro lado, isso não impede é que
}

que certas tendências correlacionais (como a vinculação entre ordem VS e inacusatividade ou o papel de tema/paciente) decorrem naturalmente da proposta defendida aqui: fundamentalmente, a postulação da CAA como condição necessária para a inversão do sujeito permite explicar por que sentenças VS apresentam tipicamente - mas não obrigatoriamente - verbos inacusativos e sujeitos não-agentivos (seção 5).

Resumidamente, portanto, propomos que a ordem linear VS se constitui, no português brasileiro, como uma construção gramatical, estando assim associada a uma configuração semântica particular. O quadro abaixo sintetiza essa configuração semântica:

Quadro 3 - Configuração semântica da construção VS

\begin{tabular}{|c|c|c|c|}
\hline $\begin{array}{c}\text { Nível-o } \\
\text { (Elementos do frame) }\end{array}$ & \multicolumn{3}{|c|}{$\begin{array}{c}\text { Nível-S } \\
\text { (Construal) }\end{array}$} \\
\hline $\begin{array}{c}\text { Entidade Focalizada, } \\
\text { Observador, Campo Visual }\end{array}$ & Entidade Focalizada & $\begin{array}{c}\text { Proeminência } \\
\text { Observador, } \\
\text { Campo Visual }\end{array}$ & Perspectiva \\
\hline
\end{tabular}

Acreditamos que este artigo apresenta uma proposta inovadora para o tratamento de um tema já extensamente discutido na literatura. Seu caráter inovador decorre do recurso a dois referenciais teóricos que ainda não

generalizações essas que poderão ser consideradas, pelo menos, candidatas a universais linguísticos. O ponto fundamental, contudo, é que, se a existência dos universais se confirmar, eles deverão ser explicados como decorrentes de necessidades universais de simbolização, pressões discursivas comuns e princípios cognitivos gerais - e não como manifestaç̃̃es de alguma faculdade da linguagem inata (CROFT, 2001; GOLDBERG, 2004; 2008; 2013). Diante disso, no que tange especificamente à construção tratada neste estudo, a primeira observação a ser feita é a de que não existe nenhuma razão programática para supor que se trate de um padrão universal. Dito isso, é interessante notar que a proposta desenvolvida aqui é compatível com - embora sensivelmente distinta de - a proposta que a proposta desenvolvida aqui é compativel com - embora sensivelmente distinta de - a proposta

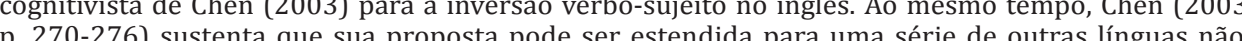
p. 270-276) sustenta que sua proposta pode ser estendida para uma série de outras línguas nãofixado no Observador) e a inversão verbo-sujeito não se limita ao português do Brasil. 
haviam sido mobilizados para descrever a ordem VS no PB: a Gramática de Construções e o instrumental analítico da semântica cognitiva. A partir de agora, é necessário que esses modelos sejam postos à prova de duas maneiras: pelo exame crítico da proposta desenvolvida aqui e pela avaliação da sua pertinência para a descrição de outras subconstruções VS do português brasileiro, como aquelas indicadas no Quadro 1.

\section{Referências}

AMBRIDGE, Ben; LIEVEN, Elena. A constructivist account of child language acquisition. In: MACWHINNEY, B.; O'GRADDY, W. (Eds.). The handbook of language emergence. Sussex: Wiley Blackwell, 2015. http://dx.doi.org/10.1002/9781118346136.ch22

AMBRIDGE, Ben; GOLDBERG, Adele. The island status of clausal complements: evidence in favor of an information structure explanation. Cognitive Linguistics, v. 3, n. 19, p. 357389, 2008. http://dx.doi.org/10.1515/COGL.2008.014

BERLINCK, Rosane de Andrade. A construção V SN no Português do Brasil: uma visão diacrônica do fenômeno da ordem. In: TARALLO, Fernando (Org.). Fotografias sociolinguísticas. Campinas: Pontes, 1989. p. 95-112.

BOAS, Hans C. Cognitive Construction Grammar. In. HOFFMANN, Thomas; TROUSDALE, Graeme (eds.). The Oxford Handbook of Construction Grammar. Oxford: University Press, 2013, p. 233-252. http://dx.doi.org/10.1093/oxfordhb/9780195396683.013.0013

BOYD, Jeremy; GOLDBERG, Adele. Learning what not to say: the role of statistical preemption and categorization in "a"-adjective production. Language, v. 81, p. 55-83, 2011. http://dx.doi.org/10.1353/lan.2011.0012

CHEN, Rong. English inversion: a figure-before-ground construction. Berlin/New York: Mouton de Gruyter, 2003. http://dx.doi.org/10.1515/9783110895100

COELHO, Izete Lehmkuhl. A ordem V DP em construções monoargumentais: uma restrição sintático-semântica. 2000. 245 fls. Tese (Doutorado em Linguística) - Universidade Federal de Santa Catarina, Florianópolis, 2000.

CROFT, William. Radical Construction Grammar: Syntactic Theory in Typological Perspective. Oxford: Oxford University Press, 2001. http://dx.doi.org/10.1093/acprof:o so/9780198299554.001.0001
CROFT, William. Radical Construction Grammar. In. HOFFMANN, Thomas; TROUSDALE, Graeme (Eds.). The Oxford Handbook of Construction Grammar. Oxford: University Press, 2013. p. 211-232. http://dx.doi.org/10.1093/oxfordhb/9780195396683.013.0012

DANCYGIER, Barbara. Conclusion: multiple viewpoints, multiple spaces. In: DANCYGIER, Barbara; SWEETSER, Eve (Eds.). Viewpoint in language: a multimodal perspective. Cambridge: University Press, 2012. http://dx.doi.org/10.1017/CB09781139084727.016

DUARTE, Inês. A família de construções inacusativas. In: MATEUS, Maria Helena Mira et al. Gramática da Língua Portuguesa. Lisboa: Caminho, 2003, p. 507-548.

FERRARI, Lilian. Distribution and function of word order variation in Brazilian Portuguese. Journal of Pragmatics, v. 1, n. 4, p. 649-666, 1990. http://dx.doi.org/10.1016/03782166(90)90035-C

FERRARI, Lilian; SWEETSER, Eve. Subjectivity and upwards projection in mental space structure. In: DANCYGIER, Barbara; SWEETSER, Eve (Eds.). Viewpoint in language: a multimodal perspective. Cambridge: University Press, 2012. http://dx.doi.org/10.1017/ СB09781139084727.005

FIGUEIREDO SILVA, Maria Cristina. A posição sujeito no português brasileiro: frases finitas e infinitivas. Campinas: Unicamp, 1996.

FILLMORE, Charles. The case for case. In: BACH, Emon; HARMS, Robert (Eds.). Universals in Linguistic Theory. London: Holt, Rinehart and Winston, 1968, p. 1-88.

. The case for case reopened. In: COLE, Peter; SADOCK, Jerrold (Eds.). Syntax and Semantics: grammatical relations. New York/San Francisco/London: Academic Press, 1977. p. 59-81.

. Frame semantics. In: THE LINGUISTIC SOCIETY OF KOREA (Ed.). Linguistics in the morning calm. Seoul: Hanshin Publishing Co., 1982, p. 111-137.

The mechanisms of "construction grammar". 1988. Disponível em: <http://journals. linguisticsociety.org/proceedings/index.php/BLS/article/viewFile/1794/1566>. Acesso em: 09 ago. 2014.

GOLDBERG, Adele. Constructions: a construction grammar approach to argument structure. Chicago: University Press, 1995.

Constructions: a new theoretical approach to language. Trends in Cognitive Sciences, v. 7, n. 5, p. 219-224, 2003. http://dx.doi.org/10.1016/S1364-6613(03)00080-9

But do we need Universal Grammar? Comment on Lidz et al. Cognition, v. 94 p. 77-84, 2004. http://dx.doi.org/10.1016/j.cognition.2004.03.003 
GOLDBERG, Adele. Constructions at work: the nature of generalization in language. Cambridge: University Press, 2006.

Universal Grammar? Or prerequisites for natural language? Brain and behavioral sciences, v. 31, p. 523-552, 2008. http://dx.doi.org/10.1017/S0140525X0800513X

Constructionist approaches. In. HOFFMANN, Thomas; TROUSDALE, Graeme (Eds.). The Oxford Handbook of Construction Grammar. Oxford: University Press, 2013. p. 15-31. http://dx.doi.org/10.1093/oxfordhb/9780195396683.013.0002

JACKENDOFF, Ray. Semantic structures. Cambridge/London: The MIT Press, 1990

LAKOFF, George; JOHNSON, Mark. Metaphors we live by. Chicago: University Press, 1980.

LAKOFF, George. Women, fire and dangerous thing: what categories reveal about the mind. Chicago: The University of Chicago Press, 1987. http://dx.doi.org/10.7208/ chicago/9780226471013.001.0001

LAMBRECHT, Knud. Information structure and sentence form: topic, focus and the mental representation of discourse referents. Cambridge: University Press, 1994. http://dx.doi. org/10.1017/CB09780511620607

When subjects behave like objects: an analysis of the merging of $\mathrm{S}$ and $\mathrm{O}$ in sentences-focus constructions across languages. Studies in language, v. 24, n. 3, p. 611682, 2000. http://dx.doi.org/10.1075/sl.24.3.06lam

LANGACKER, Ronald. Foundations of cognitive grammar: theoretical prerequisites. Vol 1. Stanford: Stanford University Press, 1987. http://dx.doi.org/10.1016/00243841(90)90017-F

. Foundations of cognitive grammar: descriptive application. Vol 2. Stanford: University Press, 1991.

Cognitive grammar: a basic introduction. Oxford: University Press, 2008. http:// dx.doi.org/10.1093/acprof:oso/9780195331967.001.0001

MICHAELIS, Laura. Type-shifting in construction grammar: an integrated approach to aspectual coercion. Cognitive linguistics, v. 15, n. 1, p. 1-67, 2004. http://dx.doi. org $/ 10.1515 / \operatorname{cog} l .2004 .001$

NARO, Anthony Julius; VOTRE, Sebastião Josué. Discourse motivations for linguistic regularities: verb/subject order in spoken Brazilian Portuguese. Probus, Dordrecht, v. 11, n. 1, p. 73-98, 1999.

NASCIMENTO, Milton do. Sur La postposition du sujet dans le portugais du Brèsil. Tese de doutorado de 3 o ciclo, Université Paris VIII, 1984.
NIKIFORIDOU, Kiki. The constructional underpinnings of viewpoint blends: the Past + now in language and literature. In: DANCYGIER, Barbara; SWEETSER, Eve (Eds.) Viewpoint in language: a multimodal perspective. Cambridge: University Press, 2012. http://dx.doi.org/10.1017/CB09781139084727.014

PEZATTI, Erotilde Goreti. A ordem de palavras em português: aspectos tipológicos e funcionais. 1992. Tese (Doutorado em Linguística e Língua Portuguesa) - Universidade Estadual Paulista, Araraquara, 1992.

PILATI, Eloisa. Sobre a ordem verbo sujeito no português do Brasil. 2002. Dissertação (Mestrado em Linguística) - Universidade de Brasília, Brasília, 2002.

PINHEIRO, Diogo. A ordem VS como construção gramatical. In: FERRARI, Lilian (Org.). Espaços Mentais e construções gramaticais: do uso linguístico à tecnologia. Rio de Janeiro: Imprinta, 2009

Sintaxe Construcionista. In: OTHERO, G. A.; KENEDY, E. (Orgs.). Sintaxe, sintaxes: uma introdução. São Paulo: Contexto, 2015.

SAEED, John. Semantics. Oxford: Blackwell, 2003.

VERHAGEN, A. Constructions of intersubjectivity: discourse, syntax and cognition. Oxford: University Press, 2005. http://dx.doi.org/10.1016/j.pragma.2008.04.002

Recebido em 20/04/2015.

Aceito em 07/08/2015. 